\title{
Importancia de la consideración de la salud mental en la gestión de la salud laboral: una responsabilidad compartida
}

\section{Importance of mental health in labour health management: a shared liability}

\author{
José Carlos Mingote Adán ', Concepción Núñez López ${ }^{2}$ \\ 1. Programa de Atención Integral al personal Sanitario Enfermo de la Comunidad Autónoma de Madrid. España. \\ 2. Asociación Madrileña de Medicina del trabajo en el Ámbito Sanitario (AMMTAS). Servicio de Prevención de \\ Riesgos Laborales del Hospital Universitario La Paz (SERMAS).Madrid. España.
}

\author{
Correspondencia: \\ José Carlos Mingote Adán \\ UVOPSE-PAIPSE \\ Pabellón 8. Ciudad Universitaria \\ 28040 Madrid. España. \\ Tfno.: + 34913303926 \\ E-mail: jmingote.hdoc@salud.madrid.org
}

Resumen

El artículo se centra en la descripción de las intervenciones que se pueden realizar desde los Servicios de Prevención de Riesgos Laborales (SPRL) y de Salud Mental ante los trastornos de salud mental y el abuso de sustancias en los trabajadores. Se requieren una atención integrada que contemple la prevenciónpromoción y asistencia al trabajador con este tipo de trastornos, así como de los derivados de factores psicosociales en el ámbito laboral. Actualmente existe un amplio acuerdo entre profesionales y gestores acerca de que debe priorizarse la atención en los Servicios de Salud Mental a las personas que padecen un trastorno mental grave, ya que son las que suelen tener una mayor discapacidad derivada del padecimiento del mismo. Para ello es necesario disponer de instrumentos que mejoren el diagnostico precoz de esos casos, así como de los recursos necesarios que permitan realizar un tratamiento efectivo. España se encuentra dentro del grupo de países con alto consumo alcohólico. Entre los trastornos relacionados con sustancias, el abuso y la dependencia del alcohol son los trastornos más frecuentes, por lo que es necesario desarrollar programas de prevención de estos trastornos con detección de sustancias en el trabajo y programas de ayuda al empleado que ya han demostrado su eficacia.

Palabras claves: Salud mental y laboral. Factores psicosociales. Trastornos mentales y T. adictivos. Procedimientos y Propuestas de intervención desde Salud Mental y Salud Laboral.

Abstract

The article focuses on the description of interventions that can be made from the Labor Risk Prevention Services and Mental Health towards mental health disorders and substance abuse in workers. Integrated care is required including prevention, promotion and employee assistance with these disorders, as well of those derived from psychosocial factors in the workplace.

Currently there is widespread agreement among professionals and managers about the fact that attention on Mental Health Services should give priority to people with severe mental disorder, as they tend to have greater disability resulting from these disorders. For this project it necessary to have tools to improve the early diagnosis of such cases as well as the resources needed to conduct effective treatment.

Spain is among the group of countries with high alcohol consumption. Among the disorders associated with substances, abuse and alcohol dependence are the most common disorders, therefore it is necessary to 
develop programs to prevent these disorders with detection of substances in the workplace and employee assistance programs which have already proved effectiveness.

Key words: Labour mental health. Psychosocial factors. Mental disorders and substance abuse. Procedures and proposals of intervention from Mental Health and Labour Health. 


\section{INTRODUCCIÓN}

Es evidente que en este momento no se puede tratar la salud mental laboral al margen de la problemática social general y de la actual crisis del sistema económicofinanciero que ya ha llegado a ser una crisis total, es decir una situación extraordinaria de ámbito global. Tras una época de abundancia y expansión económica aparentemente inagotable, hoy nos encontramos en una situación de inseguridad y estrés colectivo por frustración de expectativas comprensibles como la imposibilidad de realizar en el presente las capacidades creativas que tiene el ser humano, al no tener las oportunidades que precisan las nuevas generaciones de jóvenes: una realidad social caracterizada por altas tasas de paro y miedo a perder el empleo, y un tipo de trabajo precario que no permite la emancipación y la independencia personal

El derecho a un medio de trabajo saludable como derecho humano fundamental que promueva el bienestar de los trabajadores está en conflicto con algunas prácticas empresariales en el actual escenario globalizado en el que todo se mide por el beneficio y la rentabilidad económica a corto plazo. El mundo del trabajo y de las organizaciones de la sociedad de consumo y de riesgo global se encuentra inmerso en un proceso de cambio acelerado debido a factores tales como la grave crisis económica actual, el proceso de globalización de los mercados, que muestran una gran inestabilidad, la movilidad geográfica de las materias primas e incluso de los recursos humanos, el incesante desarrollo tecnológico, las nuevas técnicas de gestión de recursos y personas como el "downsizing" y otras formas de disminución estructural del personal laboral a fin de disminuir costes y aumentar productividad y rentabilidad, aunque ello suponga el desmoronamiento de la infraestructura económica de forma alarmante. El resultado de este tipo de prácticas extendidas es, que con independencia de la motivación y de la formación del trabajador, este se encuentra amenazado de perder el empleo o verse obligado a aceptar peores condiciones de trabajo si quiere conservarle con resignación y sumisión, que deteriora la autoestima de las personas, y a menudo reaccionan con violencia, todo lo cual tiene importantes efectos en la conducta de los trabajadores y genera nuevos riesgos para su salud. De hecho, en estos últimos años han empeorado las condiciones laborales, sobre todo las condiciones psicológicas de trabajo, según Rodríguez $^{1}$ y Ovejero Bernal ${ }^{2}$.

Esta grave situación plantea la exigencia de un código ético de conducta que regule las relaciones de obligación entre los empleados y las empresas de forma solidaria, dada la responsabilidad social de todo tipo de empresas. El fin de las organizaciones empresariales debe ser un fin social, porque una empresa "que se plantea únicamente el máximo beneficio en un corto plazo es de hecho suicida y mal va a poder sobrevivir en estos tiempos de dura competencia, en que la responsabilidad a largo plazo es una garantía de supervivencia”, según Adela Cortina ${ }^{3}$. La actual crisis económico-financiera pone de manifiesto la falta de responsabilidad social de personas sin escrúpulos, movidas exclusivamente por el afán de lucro individual, y reclama una regeneración ética global que permita recuperar la confianza en la empresa como núcleo básico a partir del cual se organizan las sociedades en los países poscapitalistas. Porque como subraya Adela Cortina:"La clave de tales sociedades no es ya tanto la familia o el Estado-nación, como las organizaciones. Una ética de las organizaciones es, pues, indispensable para reconstruir el tejido de una sociedad, para remoralizarla".

La descripción de la gestión de los trastornos de salud mental en los Servicios de Prevención de Riesgos Laborales se centra en la identificación y abordaje de aquellos trastornos mentales derivados de factores psicosociales, y de los trastornos mentales y adictivos que están presentes en la población activa. El abordaje de los problemas de salud mental se plantea partiendo de un diseño preventivo en el que se establecen estrategias de intervención en las diferentes fases del Plan de prevención de riesgos laborales. Las estrategias preventivas están contempladas en la normativa vigente y recogidas en procedimientos, protocolos y propuestas de mejora, elaboradas para conseguir dos objetivos fundamentales, la reincorporación y rehabilitación del trabajador 
y, la mejora de la calidad y productividad en el trabajo. Comisión Europea: "Mejorar la calidad y productividad en el trabajo: Estrategia comunitaria (2007-2012) de seguridad y salud en el trabajo ${ }^{4}$.

La Psiquiatría de Interconsulta y Enlace, reconocida subespecialidad de la Psiquiatría, constituye un área de conocimiento cada vez mayor que se ha desarrollado hasta enlazar con todas las especialidades médico-quirúrgicas hasta la Medicina del Trabajo, para atender los problemas psicopatológicos de los pacientes y de los profesionales sanitarios que les atienden, ayudándoles en la adquisición de las necesarias habilidades para el abordaje eficaz de los mismos. Así por ejemplo, los riesgos psicosociales del trabajo sanitario codeterminan no sólo el daño a la salud de los sanitarios, sino la calidad y la seguridad de los pacientes que atienden, según como sean gestionados a nivel individual y organizativo. En consonancia con la situación detectada es necesario establecer estrategias de intervención, en función de si la causa está relacionada con factores psicosociales presentes en el puesto de trabajo o si estamos ante trastornos mentales o aditivos no originados exclusivamente por estos factores y que pueden estar presentes en la población activa.

El desarrollo de las actuaciones y procedimientos establecidos en los trastornos de salud mental en el ámbito sanitario de la Comunidad Autónoma de Madrid persiguen un objetivo fundamental implantar y gestionar las medidas de prevención y protección con la intervención de todos los miembros de la Organización, los Servicios de Prevención de Riesgos Laborales, el Programa de Atención Integral al Profesional Sanitario Enfermo (PAIPSE), el Colegio de Enfermería y el Ilustre Colegio de Médicos de Madrid a través de la Comisión de Ayuda y Prevención del Médico Enfermo (CAYPAM), la Organización Médico Colegial, junto con todos los profesionales de la Red de Salud Mental de las Áreas Sanitarias de la Comunidad de Madrid, así como los que de forma privada o concertada puedan contribuir a mejorar la calidad de vida laboral y la seguridad de los trabajadores.

\section{MARCO LEGISLATIVO REFERENCIAL}

La salud mental de los trabajadores tiene un marco legal importante en el mandato Constitucional contenido en el articulo $40.2^{5}$ donde se encomienda a los poderes públicos velar por la seguridad e higiene en el trabajo y las Directivas Europeas como la Directiva Marco 89/391/CEE 6 por la que se establecen medidas para promover la mejora de la seguridad y la salud de los trabajadores, que en esta materia configuran el soporte básico en el que se asienta la Ley 31/1995 de Prevención de Riesgos Laborales ${ }^{7}$, el Reglamento de los Servicios de Prevención ${ }^{8}$ y demás normativa que la desarrolla. Es importante la referencia legislativa del artículo 21 de la Ley 14/1986, General de Sanidad, ${ }^{9}$ donde se determinan las actuaciones sanitarias en el ámbito de la salud laboral. Así mismo contamos con los compromisos contraídos con organizaciones internacionales como la OIT que enriquecen el contenido al incorporar sus prescripciones y darle rango legal dentro de nuestro sistema jurídico.

Destacamos los artículos de la Ley 31/1995 de Prevención más significativos en relación a la prevención y protección de la salud de los trabajadores. Así, en el articulo 14 se hace referencia a que el empresario deberá garantizar la seguridad y salud de los trabajadores, llevando a cabo la prevención de los riesgos laborales, integrando la actividad preventiva en la empresa adoptando cuantas medidas sean necesarias para la protección de la seguridad y la salud de los trabajadores. En el mismo apartado redactado según la Ley 54/2003, de reforma del marco normativo de prevención de riesgos laborales, se hace constar que el empresario desarrollará una acción permanente de seguimiento de la actividad preventiva. En relación a la vigilancia de la salud, el artículo 22, hace referencia a que el empresario tiene que garantizar la vigilancia periódica del estado de salud de los trabajadores, en función de los riesgos inherentes al trabajo y con el consentimiento de los mismos a excepción de, supuestos en que los que el reconocimiento médico sea imprescindible para evaluar las condiciones de trabajo sobre la salud o verificar si el 
estado de salud de los trabajadores puede constituir un peligro para el mismo o para los demás trabajadores u otras personas relacionadas con la empresa o cuando así esté establecido en una disposición legal en relación con la protección de riesgos específicos y actividades de especial peligrosidad. En relación con la protección de la salud de los trabajadores especialmente sensibles a determinados riesgos, en el Artículo 25, se responsabiliza al empresario de manera específica de la protección de la seguridad y salud de los trabajadores que, por sus propias características personales o estado biológico conocido, incluidos aquellos que tengan reconocida la situación de discapacidad física, psíquica o sensorial, y sean especialmente sensibles a los riesgos derivados del trabajo. A tal fin, deberá tener en cuenta dichos aspectos en las evaluaciones de los riesgos y, adoptará las medidas preventivas y de protección necesarias. Los trabajadores no serán empleados en aquellos puestos de trabajo en los que, a causa de sus características personales, estado biológico o por su discapacidad física, psíquica o sensorial debidamente reconocida, puedan ellos, los demás trabajadores u otras personas relacionadas con la empresa ponerse en situación de peligro o, en general, cuando se encuentren manifiestamente en estados o situaciones transitorias que no respondan a las exigencias psicofísicas de los respectivos puestos de trabajo.

\section{SALUD MENTAL Y SALUD LABORAL}

Son numerosos e importantes los motivos por los que debemos prestar atención a los problemas de salud mental en el trabajo. El incremento de su frecuencia, los efectos para la salud de los trabajadores, así como la interacción con la organización laboral, aumentando el absentismo con un importante coste tanto humano como económico. Los costes totales de una enfermedad incluyen no sólo los costes directos e indirectos, sino también los denominados costes intangibles, que incluyen el sufrimiento experimentado por el paciente y su familia. El potencial perdido por las personas con un determinado trastorno, a menudo marginadas de la vida económica, cultural y social, no se puede cuantificar en términos económicos pero constituye un coste inaceptable, dados las posibilidades preventivas y terapéuticas actualmente disponibles. La economía sanitaria es uno de los temas de mayor alcance mundial. Los gestores que controlan el gasto sanitario insisten en la necesidad establecer prioridades para el uso eficiente de los escasos recursos disponibles.

La atención a la salud mental en el medio laboral se considera una de las actuaciones prioritarias, teniendo en cuenta el incremento de la incidencia y su prevalencia, los efectos que causa en la salud del trabajador, en la organización y su repercusión en la calidad y productividad en el trabajo. Los estudios epidemiológicos realizados concluyen que:

1. Una gran proporción de personas padece un trastorno mental diagnosticable con criterios nosológicos precisos, con una prevalencia-vida total de 32,6\%, es decir que a lo largo de la vida un tercio de personas van a padecer un trastorno mental.

2. Sólo una pequeña parte de estas personas están siguiendo un tratamiento efectivo, la mayor parte de las veces en fases avanzadas de la enfermedad, de forma que el porcentaje de morbilidad psiquiátrica oculta oscila entre el $40 \mathrm{y}$ el $65 \%$ de casos en población general, en su mayor parte entre la población trabajadora o desempleada.

3. El padecimiento de los diferentes trastornos mentales se asocia a determinados factores de riesgo, como el género y la pertenencia a las clases sociales más desfavorecidas, lo que permite desarrollar estrategias preventivas eficaces. Destaca por su importancia el contraste cuantitativo entre las diversas prevalencias estimadas para cada población o nivel asistencial: en la comunidad, en atención primaria y en los servicios de salud mental. En consecuencia, en atención primaria se detectan menos del 50\% de los casos psiquiátricos existentes en la población, el primer filtro asistencial que podría identificarles y tratarles de forma eficiente, 
y en salud mental se atiende una escasa proporción de miembros de la comunidad con trastornos mentales, el denominado índice de penetración (porcentaje de morbilidad real que es atendida en un servicio de salud mental) que está en torno al $10 \%$ del total de casos existentes en la población general. La capacidad de identificación de los trastornos mentales depende de los conocimientos teóricos y de las destrezas de entrevista clínica. El primer filtro, la decisión de consultar, depende del paciente y de su red de apoyo sociofamiliar de la que forman parte los compañeros y jefes del trabajo, el segundo filtro es la detección del caso por el médico de atención primaria, quién decide tratar y/o derivar al paciente a salud mental, sea de forma ambulatoria o bien hospitalaria en los casos graves, según los diferentes estudios realizados en el ámbito europeo, Por estos motivos, el cuarto filtro puede ser la detección de casos en el medio laboral, porque el trabajador aporta sus propios trastornos mentales que se manifiestan en el trabajo, cualquiera que sea su origen. La consulta de los Servicios de Prevención de Riesgos Laborales puede ser el espacio más adecuado para la detección y gestión de los casos con trastorno mental, así como para su prevención y la promoción de la salud mental. Los servicios de Atención Primaria, Salud Mental y Salud Laboral pueden constituir una red de apoyo profesional eficaz que haga posible una atención integral y de calidad centrada en la comunicación con el paciente-agente principal responsable del cuidado de su propia salud. Para hacer factible este modelo orientado a la prevención y la promoción de la salud se requiere el desarrollo de mecanismos eficaces de coordinación interdisciplinar en una red única de apoyo sociosanitario profesional centrada en la comunicación con el trabajador enfermo, a través de programas integradores de salud construidos por objetivos específicos, y sobre todo en los siguientes casos:

- Enfermo con trastorno mental crónico y que requiere un tratamiento prolongado para la prevención de recaídas.

- Caso clínico complejo como con patología dual, con trastornos de personalidad asociados y que muestran una menor tolerancia al estrés, con probable repercusión en el desempeño laboral.

- Trabajadores con trastornos mentales y que tienen empleos de elevada responsabilidad social como medicina y enfermería que requieren una elevada fiabilidad y calidad que garanticen la seguridad del usuario, lo que sólo posible en un medio laboral saludable.

En los últimos años se ha detectado un incremento evidente de las enfermedades consideradas emergentes como el estrés, la depresión o la ansiedad, así como la violencia en el trabajo, el acoso, la intimidación, son responsables del 18\% de los problemas de salud asociadas con el trabajo, una cuarta parte de las cuales implica dos semanas o más de ausencia laboral. La frecuencia de estas patologías es dos veces superior en los sectores de la educación y los servicios sociales y de salud ${ }^{10}$.

En muchos países europeos, las enfermedades mentales son la causa del $45-55 \%$ del absentismo laboral ${ }^{11}$. Además, las enfermedades mentales suponen el $40 \%$ de las enfermedades crónicas y la mayor causa de los años vividos con discapacidad ${ }^{12}$. El principal ámbito de discriminación para las personas con enfermedad mental es el laboral; sólo el 5\% de las personas con enfermedad mental tiene un empleo regular, según un estudio en la Comunidad de Madrid ${ }^{13}$.

La característica fundamental de la atención a la salud mental en el medio laboral, es integrar la prevención-promoción y la atención al trabajador. Por este motivo las estrategias de prevención de las Empresas y los Servicios de Prevención de Riesgos Laborales tienen que orientar las medidas de intervención a las tres fases de la prevención: prevención primaria, secundaria y terciaria, e integrarlas en las actividades preventivas definidas en el plan de prevención. El proceso se inicia analizando la situación, con la identificación de las tareas que desempeña el trabajador, los factores de riesgo del puesto y los factores psicosociales asociados, la valoración de la salud del trabajador y la 
planificación de actuaciones preventivas, asistenciales y de formación e información. La intervención preventiva más eficaz es el reconocimiento de las vulnerabilidades individuales y de los estresores laborales objetivos, así como el tomar medidas eficaces que les disminuyan, erradiquen o les gestionen eficientemente.

Estas intervenciones preventivas, formativas y de investigación basadas en la evidencia, centradas en los procesos de trabajo, permitirán el desarrollo de la salud mental laboral y lograr así el diagnóstico precoz y el tratamiento eficaz de los distintos trastornos mentales en los trabajadores afectados en su inicio, al poder detectarles por su repercusión sociolaboral, incluso con independencia de su etiología, a través de la implementación de una cultura proactiva de aprendizaje a través del reconocimiento y estudio de los errores y de un liderazgo transformacional, según las propuestas de Pickering y Thompson ${ }^{14}$.

\section{¿De quién es la responsabilidad de la salud del trabajador?}

España, como miembro de la Unión Europea, tiene la obligación de incorporar al derecho nacional lo dispuesto en la Directiva 89/391/CEE (Directiva Marco), relativa a la aplicación de las medidas necesarias para promover la mejora de la seguridad y de la salud de los trabajadores en el ámbito laboral. La directiva establece como principio general la responsabilidad del empresario, que "debe garantizar la seguridad y la salud de los trabajadores en todos los aspectos relacionados en el trabajo" que debe integrar la prevención de riesgos laborales en el sistema general de gestión de la empresa, tanto en el conjunto de sus actividades como en todos los niveles jerárquicos de la misma. La Ley de Prevención de Riesgos Laborales (31/1995), que es el cuerpo básico de garantías y responsabilidades precisas para establecer un adecuado nivel de protección de la salud de los trabajadores frente a los riesgos derivados de las condiciones de trabajo, determina en su artículo 31 que los servicios de prevención deberán estar en condiciones de proporcionar a la empresa, el asesoramiento y el apoyo que precise en función de los riesgos existentes, así como lo referente al diseño, aplicación y coordinación de los planes y programas de actuación preventiva.

Situación de riesgo laboral es: toda aquella situación o condición laboral que tiene la posibilidad de causar un daño personal en el medio laboral. Para calificar un riesgo desde el punto de vista de su gravedad, se valorarán conjuntamente la probabilidad de que se produzca el daño y la gravedad del mismo. Tareas de riesgo son todas aquellas actividades desarrolladas en el medio laboral que por sí solas o como consecuencia de ellas, pueden desempeñar un riesgo para el trabajador. Factores de riesgo psicosocial son aquellas condiciones que se encuentran presentes en el ámbito laboral y que están directamente relacionadas con la organización, el contenido del trabajo y la realización de la tarea, y tienen capacidad para afectar tanto al bienestar y la salud del trabajador como al desarrollo del trabajo. El entorno psicosocial del trabajador lo conforma la organización, tanto en cuanto al contenido como a la realización de la tarea, así como sus actitudes, conductas y las relaciones interpersonales que establece el trabajador.

Igualmente, la Ley de Prevención de Riesgos Laborales en su Capítulo V determina que los trabajadores tienen derecho a participar activamente en cuestiones relacionadas con la prevención de riesgos laborales, a través de los cauces representativos establecidos legalmente, para asegurar que se alcancen los objetivos de prevención y se cumpla la política de la entidad, con la colaboración de todos los trabajadores y del equipo directivo de la entidad. Posteriormente el Reglamento de los Servicios de Prevención, aprobado por Real Decreto 39/1997, de 17 de enero, se dedica a desarrollar la organización de los recursos, "medios humanos y materiales necesarios para realizar las actividades preventivas", con carácter interdisciplinario y total, es decir que incluye vigilancia y control de la salud, seguridad, higiene y ergonomía y psicosociología como responsabilidad de los servicios de prevención, ya que las conclusiones que se deriven de los reconocimientos efectuados determinarán la aptitud del trabajador para el desempeño del puesto de trabajo o la necesidad de introducir o mejorar las medidas de protección y 
prevención. En este sentido se desarrollarán protocolos específicos u otros medios existentes con respecto a los factores de riesgo a los que esté expuesto el trabajador, para lo que se desarrollarán las necesarias actividades de coordinación preventiva.

Además, el trabajador responsable conocerá y actuará según las normas establecidas, sean de carácter general o de tipo específico, como en el caso de detectar una anomalía o funcionamiento deficiente, debiendo comunicarlo de forma inmediata al responsable jerárquico superior. El trabajador debe utilizar las protecciones personales que sean precisas para prevenir los accidentes y enfermedades profesionales a los que estén expuestos, como la fatiga mental y sus diferentes complicaciones, como las relacionadas con el estrés laboral. La vigilancia y el control de la salud requieren que el trabajador preste su consentimiento para la realización de reconocimientos médicos, salvo en los siguientes supuestos:

1. Cuando sea imprescindible para evaluar los efectos de las condiciones de trabajo sobre la salud de los trabajadores o para verificar si el estado de salud de los trabajadores puede constituir un peligro para el mismo, para los demás trabajadores o para otras personas relacionadas con la empresa, previo informe de los representantes de los trabajadores, al respecto.

2. Cuando así esté establecido en una disposición legal en relación con la presentación de riesgos específicos y actividades de especial peligrosidad.

En todo caso, se deberá optar por la realización de aquellos reconocimientos o pruebas que causen las menores molestias al trabajador y que sean proporcionales al riesgo, respetando siempre el derecho de intimidad y la dignidad de la persona, así como la confidencialidad de toda la información relacionada con su estado de salud según Vicente Pérez ${ }^{15}$. Estas consideraciones éticas que protegen la autonomía del paciente han sido reguladas por la Ley 41/2002 de Autonomía del Paciente que establece un marco común para la protección de los derechos humanos y la dignidad humana en la aplicación de la biología y la medicina, salvo cuando existe riesgo para la salud pública o riesgo inmediato grave para la integridad física o psíquica del enfermo. Salvo en estos casos, el paciente-agente autónomo, adecuadamente informado participa de forma corresponsable en el proceso de toma de decisiones clínicas sobre su propio estado de salud-enfermedad. El lenguaje de los derechos de los pacientes se complementa con el de la ética de la responsabilidad respecto de las decisiones que se toman con intencionalidad, conocimiento y sin control externo. Salvo que se demuestre lo contrario se trata de pacientes autónomos que en su procedimiento decisorio asumen su responsabilidad personal. El respeto de la autonomía promueve también la responsabilidad individual y colectiva compartida, debiendo establecerse los mínimos exigibles a todos mediante consensos basados en la participación solidaria y la deliberación reflexiva, como propone Gracia ${ }^{16}$.

\section{PERFIL DE RIESGO DE UN TRABAJADOR CON PROBABLE TRASTORNO MENTAL GRAVE}

Cualquier trastorno mental de moderada a severa intensidad puede producir un significativo deterioro en el desempeño de los roles sociales y familiares, como por mal cumplimiento del rol laboral, sea por omisión o por conductas inadecuadas del rol específico, como por abuso de confianza, negligencia o procrastinación. Numerosas enfermedades médicas y trastornos mentales pueden interferir en las capacidades psicomotoras, emocionales y cognitivas necesarias para el ejercicio competente del rol profesional, y entre ellas destacan los trastornos relacionados con sustancias adictivas y los trastornos graves del estado de ánimo. Los mayores problemas asistenciales dependen de los trastornos mentales caracterizados por la falta de conciencia de enfermedad (o "insight"), o por la negación de sus aspectos principales (como gravedad, repercusiones para la propia persona o para terceros, etc.), como ocurre con los problemas relacionados con el alcohol, los trastornos psicóticos y los trastornos graves de personalidad. De forma característica, al paciente con estos trastornos le resulta muy difícil asumir la conducta 
adecuada del rol de enfermo, consultan raramente de forma espontánea, y es esencial la presencia de un eficaz sistema de soporte social organizacional que permita la detección precoz de estos casos de trastornos mentales graves, así como la más rápida y eficaz instauración de su tratamiento, y la prevención de sus complicaciones más frecuentes. $E l$ trabajador afecto de un trastorno mental grave podrá ser detectado de forma precoz y recibir un tratamiento eficaz gracias a la colaboración solidaria de sus compañeros o jefe inmediato, por el examen de salud inicial o periódico, o porque él mismo demande asistencia sanitaria inducido y apoyado por sus buenos compañeros de trabajo que no le aíslan ni le impiden tener un mejor pronóstico. En cualquier caso, dada su responsabilidad ética y social, es esencial que el trabajador incapacitado sea identificado lo más precozmente posible y remitido a los profesionales más adecuados según los procedimientos legales específicos. Se recomienda además que su control posterior deba realizarse por un comité médico independiente, como desde el SPRL y no sólo por el médico que le trate.

Aunque es imposible eliminar todos los riesgos para el trabajador como para los usuarios de su servicio, es importante prevenir las consecuencias para terceros y otras responsabilidades a través de algunos procedimientos preventivos eficaces como son los siguientes: la creación de procedimientos eficaces de evaluación continua de procesos y de resultados, el establecimiento de estándares de calidad laboral y la protocolización de la actividad basada en la evidencia científica. La práctica inadecuada se caracteriza por las cuatro "DES" siguientes: que hubiera "Descuido" de un "Deber" que "Directamente" provoca un "Daño". Es decir: que el profesional no actúa con el grado esperable de pericia habitual en los miembros de una profesión, en la que se dan unas normas de calidad asistencial y unas regulaciones administrativas claramente definidas.

El término "práctica profesional inadecuada" se utiliza para referirse a la negligencia producida por mal cumplimiento del rol profesional según los estándares vigentes de calidad, tanto a nivel instrumental científico-técnico como a nivel psicosocial. La "práctica inadecuada" puede estar mediada por varios factores no excluyentes, como son:

$1 .^{\circ}$ La existencia de un trastorno mental grave no diagnosticado ni tratado adecuadamente.

2. ${ }^{\circ}$ Una insuficiente competencia profesional específica, sea en el ámbito científicotécnico y/o en el psicosocial.

3. ${ }^{\circ}$ Unas condiciones inadecuadas de trabajo, como por excesiva demanda, y apoyo social y supervisión insuficiente.

De forma habitual serán las personas próximas al trabajador las que con mayor probabilidad detecten la problemática asociada al posible trastorno mental grave. Las señales de alarma a detectar y comportamientos de riesgo a tener en cuenta serán:

- Comportamiento alterado de forma manifiesta y patrones desadaptativos de conducta: Excesiva e inadecuada irritabilidad, apatía, inhibición y falta de responsabilidad en el cumplimiento de las tareas propias del rol profesional, aislamiento, problemas de comunicación y/o frecuentes conflictos interpersonales.

- Hiper-reactividad al estrés cotidiano con baja tolerancia a situaciones estresantes comunes: como cambios en rutinas laborales, situaciones de incertidumbre y conflictos inherentes a la actividad sanitaria.

- Incumplimiento de los hábitos básicos de auto-cuidado: hábitos de salud y aspecto externo.

- Padecimiento de enfermedades crónicas (como las neurológicas) que impliquen deterioro de la capacidad funcional, necesidad de asumir el rol de enfermo y ausencia de conciencia de enfermedad.

- Situaciones estresantes específicas graves como la muerte de un familiar próximo, separación de la pareja, situaciones económicas desfavorables 
Los siguientes aspectos comportamentales objetivos pueden ser útiles como signos indicativos de la existencia de dificultades adaptativas de un trabajador para afrontar las demandas del rol ocupacional y/o de otros roles personales:

- Aspecto personal descuidado, desarreglado, y/o insano, con los signos característicos de la enfermedad alcohólica.

- Bajo rendimiento laboral con llamativa desmotivación, absentismo, escasa participación en las actividades programadas del servicio, etc., con manifiesto incumplimiento del rol laboral sanitario.

- Alta conflictividad en el ámbito de las relaciones con diferentes compañeros, frecuentes quejas de enfermos y familiares en el Servicio de Atención al Paciente, o a otros sanitarios, etc.

- Aislamiento social.

- Problemas legales repetidos.

- Conflictividad familiar persistente e intensa, con dejación de responsabilidades y comportamientos agresivos.

- Sospecha de probable trastorno mental sin constancia de que realice el tratamiento adecuado, con alteraciones del comportamiento, cambio significativo de conducta, pérdida de control ante frustraciones comunes, etc.

- Negación de responsabilidad personal con atribuciones externas y racionalizaciones continuadas de estos problemas.

Las personas con trastornos mentales pueden experimentar varias alteraciones del comportamiento en el terreno laboral que constituyen signos de alerta indicativos de la necesidad de tratamiento especializado. Así por ejemplo la Guía de Salud del MIR editada por la Organización Médica Colegial y la Fundación GALATEA, disponible en: http:// www.fgalatea.org, destaca los siguientes signos de alarma:

- Absentismo laboral, desmotivación y disminución en el rendimiento laboral.

- Desobediencia e incumplimiento de las tareas propias del rol laboral.

- Conflictos interpersonales, irritabilidad excesiva y conductas agresivas en el trabajo.

- Falta de colaboración y evitación del contacto con los compañeros.

- Dificultad en la toma de decisiones clínicas por disminución de capacidades neurocognitivas.

Signos de alarma similares a los de otras organizaciones profesionales como los propuestos por los Servicios de Salud del Médico de la Sociedad Médica de Massachussets (Physician Health Services 2003) como signos de alarma de abuso de sustancias: Cambios de personalidad, cambios de conducta con deterioro de la calidad del rendimiento en el trabajo, cambios físicos significativos, cambios en el trabajo: quejas de pacientes y compañeros, patrón inusual de prescripción de drogas, ausencias durante las guardias. Otros factores a considerar son: pérdidas personales como muertes y divorcios, deterioro del autocuidado de la salud, expresiones de preocupación por los compañeros y "el sentimiento" que puedes tener de que "algo va mal". Estas señales de alarma están disponibles en: http://www.massmed.org/ Content/NavigationMenu6HelpingY-ourselforaColleague/Sings_of_Concern_PH.htm

El descenso significativo en el rendimiento laboral, el aumento de los conflictos interpersonales y el aislamiento en el ámbito laboral constituyen signos objetivos de varios trastornos mentales como por ejemplo:

1. Ser consecuencia del consumo crónico de cannabis, que además disminuye la capacidad de introspección e impide tener conciencia de enfermedad y buscar ayuda médica.

2. Constituir los síntomas prodrómicos de una persona que padece una esquizofrenia, con síntomas tales como: falta de interés, disminución de la concentración, apatía y falta de energía, abatimiento y depresión, deterioro de la higiene y en el funcionamiento laboral. 
Estos ejemplos ponen de manifiesto la necesidad del trabajo interdisciplinario y de promover la responsabilidad corporativa con programas preventivos y de mejora del bienestar del empleado, que hagan posible el diagnóstico precoz y el tratamiento efectivo de los trastornos mentales, igual que ocurre con el resto de enfermedades.

Ante la sospecha de un probable caso psiquiátrico en el ámbito laboral se recomienda abordar al compañero probablemente enfermo de la forma más adecuada, directamente pero con respeto y motivación de ayuda genuina, con las máximas garantías de confidencialidad, por parte de dos o más colaboradores de igual rango jerárquico y el supervisor o tutor responsable, quienes le orientarán-acompañarán al profesional del Servicio de Prevención de Riesgos Laborales con la mayor diligencia.

\section{ESTRATEGIAS DE INTERVENCIÓN ANTE LOS TRABAJADORES CON PROBABLE TRASTORNO MENTAL EN EL ÁMBITO LABORAL}

La gestión de la salud mental en el trabajo ba de seguir un modelo conceptual con dos objetivos principales en la intervención ante los problemas de salud mental:

- En las condiciones de trabajo

- En las características del individuo o las consecuencias de la salud mental en el trabajador.

Las actuaciones preventivas tienen que ir dirigidas a los diferentes tipos de la prevención con medidas de intervención a nivel de prevención primaria, secundaria $y$ terciaria:

- En la prevención primaria se debe evitar la aparición del trastorno de salud mental. Estará orientada a evitar los factores precursores tanto en el lugar de trabajo como en el individuo.

- La prevención secundaria se orienta hacia el mantenimiento de la población activa, que ya padece algún tipo de trastorno, encaminada a la detección precoz de los problemas de salud mental, mejorando la salud de los trabajadores y evitar o minimizar sus consecuencias sobre el medio ambiente en el trabajo.

- La prevención terciaria estará orientada a la reincorporación y rebabilitación del trabajador con problemas de salud mental.

Las intervenciones preventivas se llevaran a cabo en cada una de las funciones que integran el Plan de Prevención de los Centros de Trabajo:

- Evaluación de Riesgos.

- Vigilancia y control de la Salud.

- Formación e información

En el plan de prevención tienen que estar integrados los procedimientos y protocolos de actuación ante de factores psicosociales de riesgo, así como, programas de actuación ante trastornos de salud mental y trastornos adictivos en el los Centros de Trabajo.

\section{Intervención Preventiva desde un Servicio de Prevención de Riesgos Laborales del ámbito sanitario}

¿Cómo abordar la prevención de los factores psicosociales de riesgo y de los trastornos mentales y adictivos en la población activa?

Las actuaciones desde los SPRL abordaran los niveles de prevención mencionados y deben de ir dirigidas tanto al medio laboral como a las características individuales de los trabajadores o a la repercusión de la salud mental sobre el individuo. 
Las actuaciones preventivas tienen que estar integradas en el Plan de Prevención de la Empresa y se planificaran partiendo de la evaluación de riesgos del puesto, de factores psicosociales y de la valoración Médico-laboral del trabajador:

\section{A. Evaluación de riesgos y factores psicosociales}

El punto de partida en la planificación de las actuaciones preventivas es la identificación y análisis de los factores de riesgo y factores psicosociales relacionados directamente con la organización, el contenido del trabajo, la realización de la tarea, las relaciones interpersonales, y demás factores que pueden ser generadores de problemas de salud mental o actuar como agravantes de los mismos:

- En las condiciones generales de trabajo se identifican los riesgos para la seguridad y salud, teniendo en cuenta, con carácter general, la naturaleza de la actividad, las características de los puestos de trabajo existentes y de los trabajadores que deban desempeñarlos

- La evaluación de factores de riesgo psicosociales se hará efectiva con métodos de evaluación como: FPSICO 89, ISTAS-21 100, PREVNLAB-PSICOSOCIAL 91, INSL 93, MARC-UV 95 y otros métodos de evaluación validados y aplicación efectiva.

- Se revisará la evaluación de riesgos con una periodicidad establecida, cuando cambien las condiciones de trabajo y con ocasión de daños para la salud.

- La valoración del riesgo siempre estará en relación con la capacidad funcional del trabajador.

\section{B. Vigilancia y control de la salud}

La valoración del estado de salud físico y psicosocial del trabajador, consiste en el examen de salud específico y la valoración psiquiátrica dirigida teniendo en cuenta las tareas o funciones que realiza el trabajador y los factores de riesgo detectados en el puesto de trabajo. En la mayoría de las ocasiones el trabajador con problemas de salud mental o de consumo abusivo de sustancias es remitido al SPRL por sus Jefes, mandos inmediatos o compañeros de trabajo, siendo en otras ocasiones detectado en un examen de salud programado o con ocasión de una consulta de salud por este u otros motivos. El control y seguimiento de la salud en estos casos se realizará con la periodicidad establecida por el facultativo que asiste al trabajador, además el trabajador tendrá que llevar a cabo los exámenes de salud específicos con la periodicidad establecida: a la incorporación al trabajo, periódico, por ausencia prolongada por motivos de salud, cuando cambien las condiciones de trabajo y con ocasión de accidentes o incidentes en el puesto de trabajo.

La valoración específica de salud mental se lleva a cabo por el médico del trabajo con un modelo de entrevista psiquiátrica dirigida y con derivación, si cumple criterios, a atención especializada a través de un modelo de comunicación entre los SRPL/Centros Salud Mental/Programas de Asistencia Especializada. Posteriormente se lleva a cabo la valoración médico-funcional con la sintomatología y disfunción que provoca y las limitaciones funcionales detectadas, así como las medidas de protección y prevención establecidas en personas con incompatibilidad laboral por sus condiciones psíquicas.

\section{Medidas de actuación preventiva}

a) Medidas intervención individuales: La actuación sobre las características individuales o de repercusión en la salud mental del trabajador deben de estar orientadas a la educación para la salud, con información de pautas de actuación en técnicas de afrontamiento en el medio laboral y en la vida diaria, así como formación e información en habilidades de comunicación, trabajo en equipo, manejo de conflictos, y estrategias específicas según las características individuales del trabajador. 
b) Medidas de intervención organizacional: Aplicación de medidas correctoras sobre los factores psicosociales, el contenido de las tareas, los procedimientos de trabajo utilizados, los turnos y la carga mental en el puesto de trabajo. Estas medidas están orientadas a evitar los factores precursores implicados en la aparición de los trastornos de salud mental en el trabajo.

c) Medidas de adaptación de tareas/o cambio de puesto por motivos de salud.

En los Centros de trabajo se aplica el protocolo de adaptación y/o cambio de puesto por motivos de salud. Después de evaluar las condiciones de trabajo y específicamente los $f$. psicosociales y su repercusión en la salud mental de los trabajadores, se pueden derivar actuaciones de adaptaciones $y / 0$ cambio de puesto con el objetivo de proteger la seguridad y salud del trabajador y/o de los compañeros y usuarios del Centro. Las medidas pueden ser de:

- Medidas de adaptación, buscando mecanismos de adaptación de las tareas y/o funciones que puedan agravar o perjudicar la salud del trabajador o de los usuarios del Centro.

- Medidas de Cambio, que se establecen cuando no se puedan llevar a cabo las medidas de adaptación y existen factores de riesgo que puedan comprometer la seguridad o salud del trabajador, de otros trabajadores y/o de los usuarios de los centros de trabajo.

d) Valoración de Incapacidad: En situaciones en las que las medidas intervención contempladas no son efectivas o no hay posibilidad de implantación dentro de la organización y el trabajador tiene una incapacidad funcional evidente para su categoría profesional y la tarea habitual que desempeña, es susceptible de valoración de incapacidad porparte de los Equipos de Valoración de Incapacidades (EVI) . En estas situaciones el facultativo del Servicio de Prevención de Riesgos Laborales elaborará un informe de valoración médico-laboral que incluya la información de atención especializada, así como la relación de medidas de intervención implantadas para poder adaptar o cambiar al trabajador dentro de la organización sin que existan riesgos para su salud ni para trabajadores y/o usuarios del centro, así como repercusiones en la calidad y productividad del centro de trabajo.. Este informe puede ser solicitado por el trabajador o por EVI con el objetivo de valorar la evaluación médico-laboral del trabajador, así como la posibilidad de implantación de medidas de prevención y protección que puedan bacer posible la adaptación de las condiciones del puesto al trabajador.

e) Formación e Información de los Trabajadores: Es imprescindible como estrategia de intervención preventiva la formación e información de los trabajadores tanto a nivel individual como en los programa de formación continuada de los centros de trabajo:

- Formación específica sobre el puesto trabajo.

- Formación gestión factores psicosociales: Manejo Conflictos, Gestión estrés, habilidades de comunicación, etc. Impartida por los SPRL y expertos en la materia.

- Información de las Evaluaciones del puesto y medidas de prevención y protección a adoptar: Información aportada por los SPRL.

f) Procedimientos de actuación en casos de situaciones conflictivas:

Protocolo de actuación en situaciones de violencia interna en el trabajo.

Los Centros de trabajo tienen que disponer de un Plan general de intervención ante conflictos internos entre sus trabajadores En las Instituciones Sanitarias se ha desarrollado un proyecto sobre el plan de situaciones conflictivas internas en trabajadores de las instituciones sanitarias de la Comunidad de Madrid. El objetivo principal estará orientado a la prevención de la violencia interna y como objetivo secundario la mejora de la asistencia sanitaria a los usuarios del Sistema Nacional de Salud. Dentro del procedimiento se establecerá un registro de conflictos internos centralizado en la 
Comunidad de Madrid, siendo los Servicios de Prevención los encargados del registro en el ámbito de su competencia, del análisis epidemiológico y de la elaboración de un MAPA de riesgos con el objetivo de establecer medidas de prevención y protección así como el control y seguimiento de su eficacia ${ }^{17}$.

Protocolo de actuación en situaciones conflictivas con los ciudadanos: Violencia externa.

Orden 212/2004, de 4 de Marzo $^{18}$ por la que se establecen las directrices y líneas generales para la elaboración de planes de prevención y atención frente a potenciales situaciones conflictivas con los ciudadanos en los centros e instituciones sanitarias públicas. Las consecuencias de las agresiones comprenden lesiones físicas y trastornos psicológicos tales como desmotivación, ansiedad, miedo a acudir al trabajo, alteraciones del sueño, deterioro de las relaciones laborales, disminución del rendimiento y/o concentración, e incluso en casos severos, trastornos de estrés postraumático. El protocolo de actuación que llevan a cabo los Servicios de Prevención de Riesgos Laborales comprende el registro de las situaciones conflictivas en una aplicación REMAC para posterior control y seguimiento, análisis epidemiológico de los datos y elaboración del MAPA de riesgos con el objetivo de establecer medidas de protección y prevención con los trabajadores que nos permitan evitar o minimizar estas situaciones así como el control de su eficacia.

\section{Gestión del probable caso con un trastorno de salud mental}

Aunque no existe ningún síntoma patognomónico de un trastorno mental específico, es fundamental conocer los síntomas característicos de los diferentes trastornos mentales graves para permitir la identificación temprana e iniciar un tratamiento precoz.

En relación a los trastornos mentales deben diferenciarse dos grupos bien definidos las patologías graves con afectación de las facultades superiores y de patologías menos graves en las que no suele estar afectadas las facultades superiores y que suelen ser compatibles con la actividad laboral:

A. Patologías Graves y habitualmente crónicas: Esquizofrenia, otras psicosis de curso crónico, T. Bipolares, T. Depresivo crónico severo, Demencias, etc:

- Alteración de funciones de nivel superior

- Suelen ser progresivas

- Evolución favorable y sin criterios de severidad suelen ser compatible con la actividad laboral

- Cuando presentan evolución desfavorable y criterios de severidad la capacidad laboral suele estar disminuida.

B. Síndromes Depresivos, Distimia, Fobias, T. Personalidad, Trastornos .Adaptativos:

- No alteración funciones de nivel superior.

- Limitaciones por otros aspectos en relación a la motivación, emotividad, aislamiento, etc.

- Compatibles en muchos casos con actividad laboral, a veces recomendada como factor beneficioso en el tratamiento y rehabilitación.

No existe una definición consensuada sobre el constructo de trastorno mental grave, éste puede variar según que el objetivo prioritario sea la planificación y gestión sanitaria, la investigación, la intervención clínica, etc., y son numerosas las posibles definiciones que se pueden encontrar al respecto en la bibliografía científica. Una revisión de las mismas de Thornicroft y Tansella en $2005^{19}$, indica como elementos comunes la necesidad de prestar atención a tres dimensiones:

- Diagnóstico: Incluyendo, de forma prioritaria, la psicosis y trastornos crónicos.

- Duración: Variable según las diferentes definiciones desde 1 a 5 años desde el inicio del trastorno. 
- Discapacidad: Operativizada en función del desempeño de roles sociales, familiares, laborales y de auto-cuidado. Según estos autores, la efectividad de los Servicios Sanitarios depende tanto de la calidad de la tecnología instrumental como de la tecnología humana (el factor humano), siendo tan importante la competencia científicotécnica personal, como los factores derivados de la actitud y de la personalidad.

Una enfermedad mental grave según el Center for Mental Health Services del Departamento de Salud y Recursos Humanos de Estados Unidos (1993), es un trastorno mental con deterioro funcional, y se define de la siguiente manera:

1. Trastorno: Cualquier trastorno DSM diagnosticado durante un período de 12 meses, excluyendo los códigos $\mathrm{V}$ (afecciones no atribuibles a un trastorno mental que son objeto de atención clínica o tratamiento, como los problemas académicos o la simulación), los trastornos por consumo de sustancias (que en el próximo DSM-V se ha propuesto llamarlo "Adicciones y Trastornos Relacionados", incluyendo juego patológico y adicción a Internet), y los trastornos del desarrollo.

2. Deterioro: Interferencia considerable en al menos una de las principales actividades de la vida que incluyen no sólo las actividades básicas de la vida cotidiana como comer o bañarse, sino también "las habilidades instrumentales (p.ej., mantener un hogar, manejar dinero, desenvolverse en sociedad, tomar la medicación prescrita), y el funcionamiento en el contexto social, familiar y laboral/educativo

Los parámetros de gravedad en adultos a considerar son según Moré y cols ${ }^{20}$.

a) La gravedad diagnóstica (psicosis, depresión mayor, trastorno neurótico severo, crisis adaptativa severa, alcoholismo y adicciones severas, trastornos alimentarios graves) combinada o no con situaciones o grupos de riesgo.

b) Comorbilidad de distintas patologías psíquicas o físicas.

c) Grado de discapacidad producido (en relación con autocuidado y salud, afrontamiento personal y social, autonomía personal y social y tratamiento).

d) Repercusión del trastorno sobre el medio familiar y social (valorando el riesgo de heteropeligrosidad).

e) Autopeligrosidad (riesgo autolítico)

f) Precariedad o agravantes de la red social (soporte social y factores que dificulten la contención y/o obstaculicen el tratamiento).

g) Características de la demanda (voluntaria o involuntaria, nivel de sufrimiento y motivación).

h) Tiempo de evolución del trastorno (agudo o crónico).

i) Complejidad del manejo terapéutico (prestaciones necesarias, trabajo en red y necesidad de coordinación entre diferentes servicios).

j) Aparición de los síntomas en etapas de especial relevancia evolutiva (por ejemplo al inicio de la actividad laboral).

El caso de los trastornos adictivos, por definición, son también trastornos crónicorecurrentes, caracterizados por el consumo compulsivo, la pérdida de control y la producción de estados emocionales negativos asociado todo ello a un elevado riesgo de estados emocionales negativos, disfunciones cognitivas y conductuales que suponen un alto riesgo de mala praxis. Esto hace necesario, no solo realizar un tratamiento completo sino controlar el cumplimiento terapéutico y prevenir las posibles recaídas a largo plazo.

La gravedad del trastorno relacionado con el abuso de sustancias adictivas, se valorarán los siguientes criterios: cantidad, frecuencia y antigüedad del uso de la sustancia, así como las percepciones del paciente, déficit de control y las repercusiones psicopatológicas, afectivas, cognitivas y conductuales. Para ello se utilizarán cuestionarios auto-administrados, pruebas de laboratorio y análisis de sustancias en sangre, orina y cabello (Art. 785 Ley de Enjuiciamiento Criminal). Estas pruebas sirven tanto para objetivar el consumo de una sustancia, gravedad del trastorno, cumplimiento terapéutico y grado de abstinencia (siempre salvaguardando la confidencialidad de los resultados). 
De forma operativa ${ }^{21}$ se incluyen en el apartado de trastorno mental grave a los pacientes con los siguientes trastornos y en los que concurran las siguientes características:

1.1. Trastorno psicótico endógeno o inducido por drogas.

1.2. Trastorno delirante crónico endógeno o inducido por drogas.

1.3. Trastorno bipolar tipos I, II y III si existe comorbilidad con trastorno adictivo.

1.4. Demencia y deterioro cognitivo de causa psico-orgánica (trastorno mental severo, drogas, etc.).

1.5. Paciente con diagnóstico de trastorno grave de la personalidad, si existe comorbilidad con consumo de drogas (de forma prioritaria en caso de trastorno de tipo límite, antisocial o paranoide).

1.6. Trastorno disruptivo de conducta.

1.7. Trastorno mental grave que precise ingreso psiquiátrico.

Igualmente se incluyen en este apartado a los pacientes con trastornos adictivos que cumplen los siguientes criterios:

1.8. Trastorno adictivo y ejercicio de especialidad de riesgo (como anestesia, cirugía, ginecología, urgencias, intensivos, farmacología clínica, farmacia hospitalaria y demás servicios intervencionistas).

1.9. Presencia de patología dual.

1.10. Presencia de consumo durante la práctica profesional y/o en el lugar de trabajo (detectado en anamnesia).

1.11. Fracaso previo en al menos dos tratamientos frente a la adicción.

1.12. Policonsumo.

Criterios de detección del riesgo para si mismo o para terceros.

En el caso de los trastornos mentales graves se considerará la posibilidad de riesgo para la seguridad del propio paciente o para terceros:

1.13. Durante la evaluación del paciente se valorará la existencia de riesgo mediante:

1.13.1. La confirmación del mismo por el propio paciente a lo largo de la entrevista de apertura de historia y/o la entrevista clínica.

1.13.2. Información al respecto por parte del Servicio de Prevención de Riesgos Laborales que corresponde al paciente.

1.13.3. Quejas y/o reclamaciones de pacientes sobre ese profesional recogidas por escrito, que hagan presuponer el riesgo.

1.13.4. Manifestaciones en este sentido, reiteradas y concretas, de compañeros y/o supervisores.

1.13.5. Manifestaciones en este sentido por parte de familiares o acompañantes.

1.13.6. Conocimiento del terapeuta responsable del caso al realizar la evaluación y abordaje del mismo.

1.14. Se tendrán en consideración los siguientes elementos:

1.14.1. Historia psiquiátrica y laboral previa.

1.14.2. Tipo de diagnóstico/s.

1.14.3. Gravedad clínica. Identificando la presencia de:

- Pensamientos de auto/hetero-lesión.

- Ideación autolítica.

- Delirios o alucinaciones francas.

- Cuadro de agitación o pérdida del autocontrol.

- Patología orgánica asociada.

- Situación de consumo y/o abstinencia de drogas que comporte un peligro para la praxis. 
1.14.4. Especialidad de riesgo (médicos y enfermeros de urgencias, de cuidados intensivos, cirujanos, anestesistas, y/o otros puestos de elevada responsabilidad respecto a terceros).

1.14.5. Condición de "trabajador especialmente sensible a determinados riesgos" informada por su correspondiente Servicio de Prevención de Riesgos Laborales (en función del Art. 25 de la L.P.R.L.).

1.14.6. Condiciones de trabajo de elevado riesgo psicosocial.

\section{Procedimiento operativo}

El procedimiento operativo que se realice debe orientarse a la recuperación de la salud del trabajador enfermo y a la prevención de los posibles riesgos sociales que se puedan derivar, aunando tanto el respeto a los legítimos derechos individuales recogidos en la actual Constitución Española, como la garantía de los derechos sociales esenciales, como es la salud. Para mejorar la calidad de vida laboral, la eficiencia de la institución y la prevención de responsabilidades, es necesario contar con unas normas organizacionales claras y con unos procedimientos reguladores eficaces que promuevan el desarrollo de una práctica médica adecuada y cuando exista riesgo significativo de daño grave a otras personas, se debe priorizar el deber de protección social sobre los legítimos derechos individuales, tomando y documentando cuantas decisiones y medidas se consideren necesarias, tales como: la advertencia del riesgo al interesado, al supervisor jerárquico responsable y a sus familiares, además de tramitar la solicitud de incapacidad laboral, de su hospitalización voluntaria o involuntaria y del seguimiento cuidadoso del caso. La determinación del grado de competencia de un trabajador con un trastorno mental grave que produce un deterioro en el juicio de realidad, como en los problemas relacionados con sustancias adictivas, los trastornos del estado de ánimo y los trastornos psicóticos, requiere de una cuidadosa valoración individual para determinar si tales personas son capaces o no de hacerse cargo y gestionar adecuadamente las demandas propias de su rol profesional para los recursos disponibles con los que cuentan. Para ello se deberá realizar el examen del estado mental del trabajador enfermo por un médico psiquiatra para valorar si esa persona es capaz de sopesar las distintas posibilidades, sus resultados previsibles y la relación beneficios/riesgos, razonar y tomar decisiones prudentes con tareas específicas de su trabajo. Además de realizar las pruebas complementarias necesarias se realizará un juicio formal con levantamiento de acta de su capacidad-incapacidad personal. Una vez declarada incompetente una persona se la priva del derecho a practicar su profesión y a los derechos que se consideren necesarios. Si la capacidad disminuida o la pérdida de capacidad originada por el trastorno mental, le impiden o dificultan de forma significativa asumir las responsabilidades propias del rol profesional, se valorará la presencia de cualquier trastorno mental de intensidad moderada o grave, sea primario o secundario.

En el caso de los profesionales sanitarios (PS), como en otros profesionales de otros sectores de alta fiabilidad y responsabilidad social, pueden tener lugar unas consecuencias especialmente graves para terceros, además de los peligros de daño para sí mismo. Más allá de la competencia científico-técnica del PS es necesario valorar también su competencia psicosocial, habilidades de comunicación y de respeto a la individualidad del enfermo, en cuanto a sus preferencias y creencias propias, a su intimidad y a la confidencialidad de la relación. Cuando se detecte en cualquier PS la presencia de un patrón desadaptado de conducta, con deterioro significativo de su actividad socio-laboral, por mal cumplimiento de las responsabilidades propias de su rol profesional, sea por acción inadecuada o por omisión; los demás PS que lo conozcan tienen la obligación individual de comunicar al superior jerárquico inmediato la existencia de tales disfunciones del rol profesional. No actuar así constituye una complicidad negligente con el compañero desadaptado, que contribuye al aumento de los riesgos derivados para él mismo y para terceros. El supervisor responsable comprobará con la mayor discreción y diligencia posible, la información recibida a través de otros compañeros del trabajo y de los familiares del compañero enfermo, y la transmitirá al responsable del Servicio de Prevención de Riesgos Laborales. Desde este servicio se confrontará a la persona afectada con sus alteraciones de conducta, 
guiándose por criterios preventivos y terapéuticos, para lo que podrá contar con el apoyo de los especialistas que considere más adecuados al caso concreto, siempre con la máxima confidencialidad y respeto a la dignidad y buena imagen del afectado.

En todo caso se considerarán las siguientes dimensiones esenciales:

- La existencia o no de conciencia de enfermedad en el trabajador enfermo, de su gravedad y de la importancia de sus repercusiones probables.

- El grado de adherencia al tratamiento.

- La disponibilidad de apoyo socio-familiar. Se estudiará su situación familiar, para identificar la figura clave y tras contactar con ella evaluar su grado de conocimiento de la enfermedad del trabajador.

- Existencia de tratamiento psiquiátrico previo.

- La posibilidad de establecer un compromiso terapéutico y de controlar su eficacia y continuidad y para la prevención de recaídas y la realización aleatoria de la determinación de los niveles de fármacos y/o de presencia de tóxicos.

- La valoración de los riesgos que pudieran resultar para la salud propia y de terceros

El manejo de las bajas y las altas laborales en los PS presentan connotaciones económicas, sociales y laborales, de gran complejidad, por lo que es esencial evaluar y registrar su pérdida de capacidad productiva. La responsabilidad en el manejo de las bajas laborales es del médico de familia, quien podrá utilizar como asesores cualificados a los especialistas hospitalarios o al médico de empresa. Cuando haya discrepancias irreconciliables entre el paciente y sus médicos, se contará con la inspección médica para negociar con aquel sobre su baja o alta laboral.

Se realizará la tramitación de solicitud de invalidez permanente de un PS cuando tras haber cumplido el tratamiento prescrito, presenta limitaciones anatómicas o funcionales objetivables graves y previsiblemente definitivas que disminuyen o anulan su capacidad laboral, según la Ley 42/94 del 30 de Diciembre de 1994.

Se valorará la indicación de ingreso psiquiátrico voluntario o involuntario por el tipo e intensidad de los síntomas psicopatológicos, ausencia de conciencia de enfermedad, el grado de desconexión del paciente con el medio y el riesgo para sí mismo o para otras personas. Lo que ocurre habitualmente en el caso de trastornos psicóticos, depresiones graves, y trastornos del comportamiento de tipo violento. Si el traslado es voluntario se debe solicitar un consentimiento informado por escrito. Si es involuntario, es recomendable solicitarlo a la familia, y además hacer un parte al juzgado de guardia correspondiente por medio de un aviso telefónico, fax o escrito con acuse de recibo en las 24 horas siguientes al traslado. Siempre hay que registrar en la historia clínica del paciente la valoración clínica, la medicación administrada y el motivo de traslado, por dos psiquiatras diferentes.

El ingreso involuntario está regulado en la Jurisdicción Civil por Ley 13/83 del 24 de Octubre de Reforma del Código Civil en materia de Tutela (B.O.E. n $^{\circ}$ 256, 26 Diciembre 1983). Su objetivo es garantizar la seguridad del enfermo y de las personas que le rodean, sobre todo en el caso de trastornos clínicos graves, en presencia de riesgo suicida y de otras conductas de riesgo (como las adicciones), así como por resistencia y falta de adherencia al tratamiento. En estas situaciones de crisis se deben evitar las actitudes amenazantes y polemizar con el paciente, aunque tampoco se le debe dar la razón y someterse a sus manipulaciones engañosas. Al alta se debe hacer la derivación más conveniente para asegurar su seguimiento ulterior, contando con las preferencias del paciente y con las mejores posibilidades asistenciales disponibles.

En el caso de los Problemas Relacionados con el Alcohol y de otras sustancias de abuso, es preciso realizar una evaluación médica y psicológica completa, y valorar si el paciente presenta dependencia alcohólica, en cuyo caso se realizará desintoxicación, bien hospitalaria, bien ambulatoria (teniendo en cuenta la gravedad somática del caso y el apoyo familiar disponible). Tras ello, se pasa al período de deshabituación, donde también pasan directamente los pacientes con diagnóstico de abuso alcohólico. En esta fase se 
combina, tratamiento farmacológico con abordaje psicoterapéutico. El tiempo de seguimiento de los pacientes es un año.

\section{Propuesta de actuación desde un Servicio de Prevención de Riesgos Laborales del ámbito sanitario}

En la propuesta de actuación planteada desde un Servicio de Prevención del ámbito sanitario se describe el protocolo a seguir que comprende las actuaciones que se han de llevar a cabo ante trastornos mentales y trastornos adictivos presentes en los trabajadores del ámbito sanitario:

1. Establecer si se cumplen los criterios diagnósticos:

- Sospecha Clínica.

2. Valoración del puesto:

- Riesgos y factores psicosociales.

3. Valoración de la salud:

- Psiquiatría Dirigida y protocolo específico.

4. Propuesta Terapéutica:

- Adherencia, seguimiento.

5. Valoración de Repercusión-Clínico Laboral.

6. Intervenciones en la Organización.

7. Coordinación con Instancias Externas.

En el protocolo de actuación se describe de una manera secuencial las actuaciones a desarrollar ante la sospecha o comunicación de un trabajador con trastorno mental y/o adictivo en los centros de trabajo del ámbito sanitario. El trabajador habitualmente es detectado por sus compañeros, mando intermedio, jefe del servicio/unidad o por otros dispositivos asistenciales relacionados. En otras ocasiones es detectado en un examen de salud inicial o periódico en el Servicio de Prevención del centro de trabajo. Una vez detectado y que acude a la consulta de salud laboral se hace una evaluación de la salud específica y la valoración psiquiátrica dirigida, la valoración de los riesgos del puesto, derivación si procede y valoración de la información aportada por los dispositivos de salud mental en un ejemplo concreto. Finalmente se determinan la valoración funcional del trabajador, así como las medidas de intervención preventiva su implantación, control, seguimiento y valoración de su eficacia. En casos de ineficacia de las medidas de prevención implantadas o cuando no hay posibilidades de implantación por la organización y el criterio de valoración médico funcional es de no aptitud, el trabajador tiene la posibilidad de valoración de incapacidad laboral por los equipos de valoración de incapacidades.

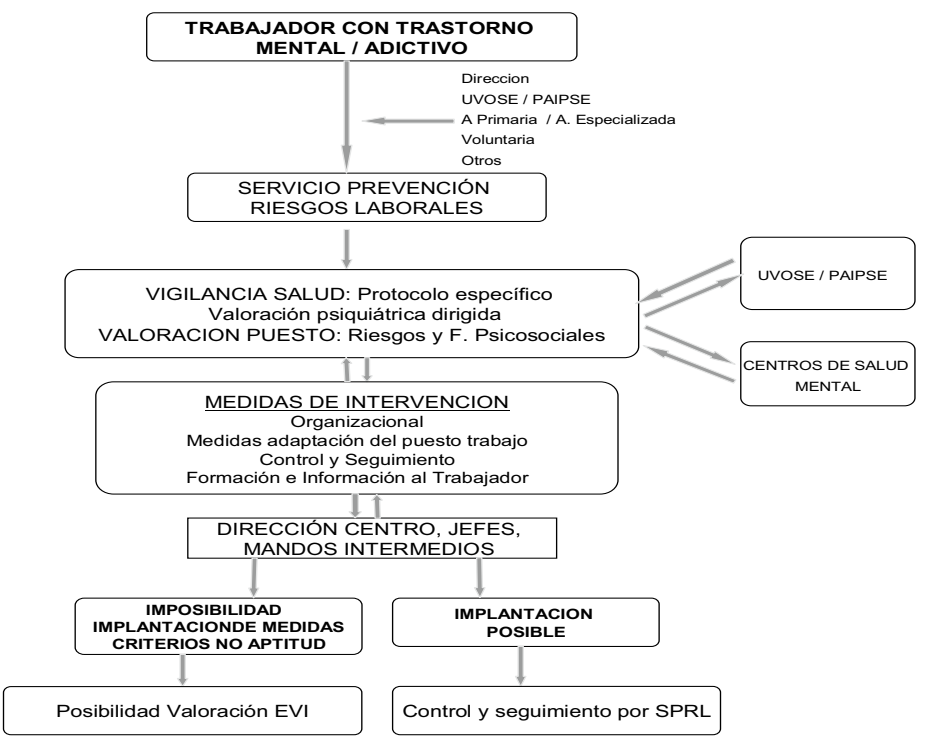




\section{Circuito de comunicación entre el SPRL y otros dispositivos asistenciales.}

En la propuesta de actuación se determina el circuito de comunicación con los dispositivos de atención especializada y primaria así como programas de asistencia integral sanitaria a profesionales, relacionados con la valoración de los trastornos de salud mental y trastornos adictivos, necesario para un adecuado plan terapéutico y control y seguimiento del trabajador.

Los Servicios de Prevención de Riesgos Laborales deben establecer una continua comunicación con los dispositivos relacionados fundamentalmente con atención primaria, atención especializada y programas de asistencia sanitaria específica al sanitario enfermo.

También se establecerá un circuito de comunicación con los Jefes, Mandos Intermedios y Direcciones correspondientes para la adecuada implantación de las medidas de prevención y adaptación del trabajador al puesto de trabajo, así como para la revisión periódica de su eficacia.

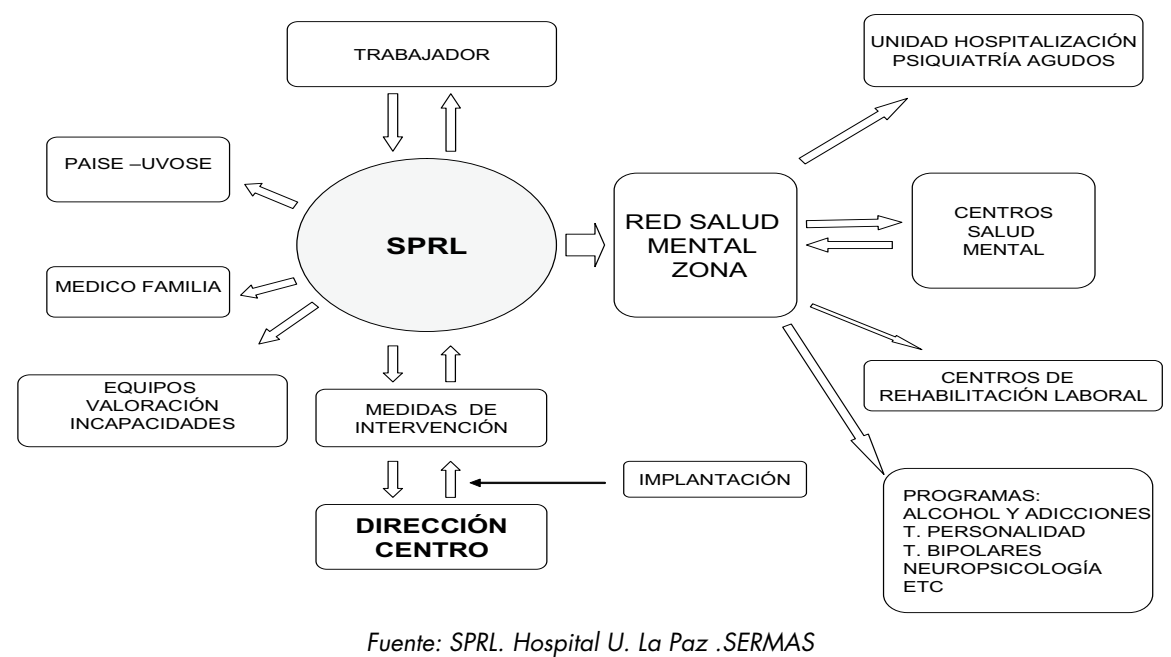

\section{Objetivos de la derivación al Servicio de Salud Mental}

1. Valoración psiquiátrica y psicológica del trabajador enfermo que se considere necesario, según el protocolo de interconsulta y enlace desarrollad, así como su seguimiento hasta el alta clínica y laboral, según los criterios de inclusión y de salida que se consideren más adecuados.

2. Colaboración con los profesionales de otros centros sanitarios para conseguir realizar el mejor tratamiento posible en cada caso. Para ello se elaborarán los protocolos de coordinación con los servicios y programas que sean convenientes.

3. Elaboración de documentos normalizados, tales como contratos terapéuticos, consentimientos informados, etc.

4. Así mismo, se realizarán las funciones y cometidos que dentro del objetivo general del programa se consideren sean convenientes.

\section{¿Quién hace las derivaciones?}

Las derivaciones se harán de forma preferente desde:

- Los Servicios de Prevención de Riesgos Laborales de las Áreas Sanitarias en los casos en que se considere conveniente, sea por su gravedad clínica, dificultad de manejo terapéutico y/o grado de interferencia en el desarrollo de su actividad laboral.

- Los médicos de Atención Primaria...

- Los Servicios de Psiquiatría de los Distritos y Áreas Asistenciales en los casos en que se considere conveniente, sea por sus características clínicas, por confidencialidad, 
consideraciones terapéuticas y/o por el grado de interferencia en el desarrollo de su actividad laboral.

- A petición propia.

\section{PROTOCOLO CLÍNICO BÁSICO}

1. Evaluación clínica y psicométrica.

2. Solicitud de pruebas complementarias e interconsultas en los casos en los que se considere conveniente. Algunas patologías requieren utilizar unos procedimientos diagnósticos y terapéuticos específicos, como en el caso de los trastornos adictivos, que en cada caso se llevarán a efecto en los dispositivos más convenientes, sea de forma ambulatoria o de ingreso hospitalario.

3. Se propondrá un tratamiento integral con las intervenciones farmacológicas, psicológicas y sociales que permitan resolver el trastorno concreto, mejorar el bienestar del sanitario y del usuario, así como la eficiencia del Sistema Público de Salud.

Cuando, según los criterios establecidos, se identifique a un trabajador como posible trastorno mental grave con riesgo para si mismo o terceras personas se agilizará, en la medida de lo posible, la evaluación preferente o urgente del caso.

Se propondrá un tratamiento asistencial psico-farmacológico y se valorarán los siguientes aspectos fundamentales:

1. Valoración del grado de discapacidad mental y necesidad de incapacidad temporal $^{1}$ (en un primer momento) y/o permanente (si se considera oportuno a lo largo del proceso asistencial).

2. Conveniencia de intervención médica y psiquiátrica hospitalaria urgente (voluntaria o involuntaria) en su Servicio de Urgencias correspondiente.

3. Comunicación con la familia del profesional sanitario con posible trastorno mental grave.

4. En caso de los médicos internos residentes, comunicación con su tutor de residentes.

5. Comunicación con el SPRL al que esté adscrito el profesional, a fin de controlar los posibles riesgos laborales que puedan verse incrementados por sus condiciones de salud y valoración del riesgo para si mismo y para terceros de forma extensible al lugar de trabajo. Será función de este servicio la valoración sobre la aptitud o no del paciente en su puesto de trabajo, su posible consideración como trabajador especialmente sensible y la valoración del riesgo profesional.

Si el SPRL lo considera oportuno tras el proceso de vigilancia de la salud y evaluación de aptitud profesional, comunicará el riesgo a Gerencia. Si el enfermo no acepta el criterio de no aptitud para el trabajo, pero se estima riesgo para terceros, se recomienda notificar esta contingencia a la Inspección Sanitaria (que puede aplicar igualmente la baja laboral por motivos médicos según normativa legal vigente), y por el La Gerencia Sanitaria tiene la responsabilidad sobre el funcionamiento asistencial de su entidad sanitaria, por lo que, si lo considera oportuno, comunicará el riesgo para terceros al juez o fiscalía de incapacidades, así como la oportunidad de valorar la responsabilidad deontológica $y$ posible riesgo de mal praxis por parte del Colegio Profesional del trabajador enfermo.

\section{INFORMACIÓN AL PACIENTE CON POSIBLE RIESGO PARA SI MISMO Y/O PARA TERCEROS Y PLAN TERAPÉUTICO}

Todos los pacientes que, a lo largo del proceso de evaluación y/o tratamiento, se califiquen como "trastorno mental grave y riesgo para si mismo o terceras personas" serán informados de tal condición. 
1. Si el paciente acepta dicha condición:

1. Firmará un contrato terapéutico comprometiéndose a seguir el plan terapéutico propuesto, previa valoración de su capacidad (según Documento Sitges 2009). En el caso de pacientes con problemas adictivos, dicho plan comportará la realización de un tratamiento de desintoxicación, deshabituación y rehabilitación, con el seguimiento posterior y controles toxicológicos necesarios según criterio clínico.

2. Si el paciente no acepta dicha condición o existe incumplimiento del plan terapéutico:

1. Se considerará la necesidad de gestionar el tratamiento no-voluntario o el internamiento involuntario mediante solicitud judicial.

2. Se informará de forma inmediata a su Servicio de Prevención de Riesgos Laborales, a fin de controlar los posibles riesgos laborales que puedan verse incrementados por sus condiciones de salud y valoración del riesgo para si mismo y para terceros de forma extensible al lugar de trabajo (Será función de este servicio la valoración sobre la aptitud o no del paciente en su puesto de trabajo, su posible consideración como trabajador especialmente sensible y la valoración del riesgo profesional).

3. Si el S.P.R.L. lo considera oportuno tras el proceso de vigilancia de la salud y evaluación de aptitud profesional, comunicará el riesgo a Gerencia.

4. La Gerencia Sanitaria tiene la responsabilidad sobre el funcionamiento asistencial de su entidad sanitaria, por lo que, si lo considera oportuno, comunicará el riesgo para terceros al juez y la oportunidad de valorar la responsabilidad deontológica y posible riesgo de mal praxis al Colegio Profesional del sanitario enfermo.

5. Se informará al Colegio Profesional del PS enfermo porque el persistente incumplimiento terapéutico en pacientes "con riesgo para la praxis", la no realización de controles toxicológicos y/o tres controles consecutivos positivos, será causa de información para solicitar asesoramiento sobre el procedimiento clínico-laboral más adecuado a seguir, de forma individualizada y confidencial.

\section{CONCLUSIONES}

Tradicionalmente se ha tejido un muro de silencio frente a los trabajadores enfermos por patología mental o adictiva, tanto por los propios compañeros como por la propia administración responsable de los centros. Se propone que ante la sospecha de un probable trastorno mental grave con posible riesgo para sí mismo o para terceros se proceda de la siguiente manera:

- Comunicación verbal con el propio afectado sugiriendo la necesidad de consulta profesional en su SPRL y/o con el superior inmediato del trabajador afectado.

- El Superior le sugerirá verbalmente la posibilidad de consulta con el SPRL.

- Si accede: se le evalúa su salud mental actual.

- Si no accede: Elaboración de un escrito por parte de compañeros y superior, en el que de forma esquemática, fechada y objetiva se señalen conductas disruptivas observadas, conflictos en el lugar de trabajo, sintomatología clínica observada y otros datos de interés. Este escrito se hará llegar al SPRL.

El constructo "trastorno mental grave" incluye un conjunto de diferentes entidades nosológicas, que se presentan en una persona de forma continua o episódica- recurrente durante unos dos años de media y que cumplen unos determinados criterios diagnósticos de gravedad clínica y de evolución crónica; de forma que, para atenderlos, se debe disponer de unos recursos asistenciales adecuados. 
Actualmente, hay un amplio acuerdo entre profesionales y gestores acerca de que debe priorizarse la atención en los Servicios de Salud Mental a las personas que padecen un trastorno mental grave, ya que son las que suelen tener una mayor discapacidad derivada del padecimiento del mismo (Thornicroft y Tansella, 2005). Por otro lado, es necesario disponer de instrumentos que mejoren el reconocimiento de los casos más graves y ayuden a la toma de decisiones en su derivación (Moré Herrero et al., 2008).

Los SPRL son imprescindibles en la detección precoz de los factores psicosociales de riesgo, trastornos de salud mental y adictivos, por la accesibilidad a los trabajadores, por el conocimiento de los puestos de trabajo y del estado de salud de los trabajadores. Par lograr estos objetivos los profesionales sanitarios pueden adquirir herramientas sencillas y eficaces para la detección precoz y el tratamiento efectivo de los trabajadores que padecen trastornos mentales como hacen con las demás enfermedades.

La propia Institución Sanitaria, los servicios de Prevención de Riesgos Laborales en colaboración con los de Salud Mental y con los medios que sean necesarios deben garantizar la calidad de vida laboral y la seguridad de los trabajadores, a través del desarrollo de los programas más convenientes, con las máximas garantías bioéticas y confidencialidad.

Se potenciará la relación con los sindicatos representativos del sector sanitario y los colegios profesionales correspondientes a los casos que proceda a fin de realizar cuantas intervenciones preventivas sean convenientes para mejorar la calidad laboral de los trabajadores sanitarios y facilitar la asistencia clínica de los casos afectados.

Es necesario potenciar la investigación epidemiológica en la relación a la Salud Mental de los profesionales de la sanidad y sus condiciones de trabajo. Es necesaria la intervención de todos los actores de la organización para prevenir y controlar los efectos para la salud de los factores psicosociales de riesgo.

Son necesarias con carácter permanente estrategias de formación e información integradas en la formación continuada de los Centros de Trabajo y dirigidas a Trabajadores, Delegados de Prevención Jefes, Mandos Intermedios y Direcciones, en políticas y procedimientos de prevención de la violencia, habilidades de comunicación, trabajos en equipo, manejo de conflictos etc. Los SPRL precisan formación específica en la identificación y estrategias de intervención en relación a los factores psicosociales, trastornos mentales y adictivos en la población laboral.

Los especialistas y actores sociales señalan la necesidad de disponer de investigaciones que informen acerca de la efectividad de diversas estrategias, modelos y programas preventivos que se han aplicado muchas veces en forma empírica, sin un sustento sólido demostrable por investigación.

Cuando el Colegio Profesional tenga conocimiento de un profesional del SERMAS con un posible trastorno mental grave que suponga riesgo para sí mismo y/o para terceros, facilitará su evaluación psiquiátrica y velará, según sus propios protocolos de actuación, por la responsabilidad deontológica del profesional sanitario.

\section{REFERENCIAS BIBLIOGRÁFICAS}

1. Rodríguez A. Psicología de las Organizaciones. Promolibro, Valencia. 1988.

2. Ovejero Bernal A. Psicología del trabajo en un mundo globalizado. Biblioteca Nueva, Madrid. . 2006.

3. Cortina A. 2005. Ética de la empresa. Trotta, Valencia

Vicente Pérez AJ. 2005. Prevención de Riesgos Laborales. ESIC, Madrid.

4. Comisión Europea: "Mejorar la calidad y productividad en el trabajo: Estrategia comunitaria de seguridad y salud en el trabajo (2007-2012).

5. Constitución Española. Articulo 40.2. Salud laboral. BOE-A-1978-31229 
6. Directiva Marco 89/391/CEE,(6) del Consejo del 12 Junio 1989: DOCE Serie L $n^{\circ}$ 183. por la que se establecen medidas para promover la mejora de la seguridad y la salud de los trabajadores

7. Ley 31/1995 de Prevención de Riesgos Laborales. (BOE 269/1995 de 10-11-1995)

8. Real Decreto 39/1997 del Reglamento de los Servicios de Prevención.

9. Ley 14/1986, de 25 de Abril, General de Sanidad, en su Capitulo IV: Artículo 21 donde se determinan las actuaciones sanitarias en el ámbito de la salud laboral. BOE-A-1986-10499.

10. Como adaptarse a los cambios en la sociedad y en el mundo del trabajo: Una estrategia comunitaria de seguridad y salud en el trabajo 2002-2006.Comisión Europea.

11. OMS, Mental Health: facing the challengs, building solutions.2005.

12. Ministerio de Sanidad y Consumo. Estrategia de Salud Mental del Sistema Nacional de Salud. 2006.

13. Comunidad de Madrid y Obra Social de Caja Madrid. Estigma social y enfermedad mental. 2006.

14. Pickering S, Thompson J. Gobierno clínico y gestión eficiente. Cómo cumplir la agenda de modernización. Elsevier España. 2010.

15. Vicente Pérez AJ. Prevención de riesgos laborales. ESIC Madrid. 2005.

16. Gracia D. Fundamentos de Bioética. Triacastela. Madrid. 2007.

17. Protocolo de actuación en situaciones conflictivas con los ciudadanos: Violencia externa. Orden 212/2004, Madrid a 4 de Marzo 2004.

18. Jornadas de Prevención de la Violencia Interna en las Instituciones Sanitarias. Hospital ClínicoAMMTAS. Madrid 28 Enero 2011.

19. Thornicroft, G. y Tansella, M. La Matriz de la Salud Mental. Manual para la mejora de servicios. Fundación Española de Psiquiatría y Salud Mental. Madrid: Editorial Triacastela, 2005.

20. Moré, M.A., Jiménez, M.A., Muñoz, P.E., Muñoz, A. y Zufía, J. Estudio preliminar dirigido a la construcción de un cuestionario de derivación de la atención primaria a los servicios de salud mental. Actas Españolas de Psiquiatría 2008; 36(4); 210-217. 2008.

21. Mingote, J.C., Del Pino Cuadrado P., Gálvez Herrer, M, Gutiérrez García, M.D., Sánchez Alaejos, R. Utilidad preventiva del constructo "trastorno mental grave" en el ámbito sociosanitario. Medicina y Seguridad en el Trabajo 2010,56(221): 306-322. 2010.

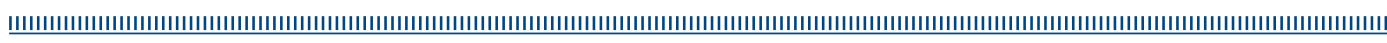

